\begin{tabular}{|ccc}
\hline Sournals & $\begin{array}{c}\text { INTERNATIONAL JOURNAL OF } \\
\text { ORGANIZATIONAL LEADERSHIP }\end{array}$ & $\begin{array}{c}\text { INDUSTRIAL } \\
\text { MANAGEMENT } \\
\text { INSTITUTE }\end{array}$ \\
\hline \hline
\end{tabular}

\title{
Examining the Role of Organizational Virtue in Professional Ethics Augmentation
}

\author{
Habib Ebrahimpour1,", Vakil Heidari Sareban² \\ Associate Professor of Public Administration, University of Mohaghegh Ardabili, Ardabil, Iran \\ ${ }^{2}$ Department of Geography, University of Mohaghegh Ardabili, Ardabil, Iran
}

\begin{abstract}
Keywords:

Organizational Virtue, Professional Ethics,

Maskan Bank of Ardabil

Received

30 May 2017

Received in revised form

14 December 2017

Accepted

19 January 2018

Correspondence:

Ebrahimpourh@yahoo.com

As a new branch of ethics, professional ethics seeks to respond to the ethical issues of various professions. Today, professional ethics has a strategic role in businesses, and strategic management specialists have identified appropriate ethical principles in an organization as a precondition for a quality strategic management. Professional ethics is the most important tool of business and administrative activities, but unfortunately in our religious community, there is no respect for professional ethics in the workplace. Organizational virtues which refer to the qualified behavior of organization members can play an important role in displaying the professional ethics. So, this study examines the role of organizational virtue in the development of professional ethics of Maskan Bank staff in Ardabil. To this end, organizational virtue was examined in five categories including optimism, trust, compassion, integrity, and forgiveness. Professional ethics was examined in eight dimensions of accountability, virtue and competitiveness, honesty, respect for others, respect towards social values and norms, justice, compassion for others, and loyalty. This applied study is a descriptive-survey research using a questionnaire. The sample included 118 employees of Maskan Bank of Ardabil. Data analysis was performed using Pearson and multivariate regression analysis. The results indicated that organizational virtue had a significant positive effect on the staff's professional ethics. Optimism had the highest impact on the professional ethics of the staff and the least significance was related to forgiveness.
\end{abstract}

(C)AIMI Journals

\section{Introduction}

The concept of professional morality is relatively a new phenomenon in economics. It studies the relationships between professions and describes the moral responsibilities of organizations, identifies moral problems in different professions, and tries to solve them (Pennino, 2002). Depending on the nature of the organization, the degree of considering morality and 
professional behavior of the staff is effective in the fate of organization and its survival. The importance of ethics and professional behavior of the staff reduplicates when the organization faces financial and other problems in felicity of its nature. The community which deals with banking always desires that its staff provide financial services with the best quality leaning on reliability and confidence of professional operation of the group. Professional ethics is one of the most important tools in the development of commercial and administrative activities implying that staff should not obtain special privileges which are advantageous for themselves and disadvantageous for others through inappropriate manners and by violating peaceful competition (Jos, 2006). Professional ethic has a considerable impact on the activities and outcomes of organizations in such a way that it increases productivity, improves relationships, and reduces probable risks, because when it is dominant in an organization, it facilitates the flow of information which in turn makes the head be already aware of the occurrence of an undesirable event. Organizational virtue is one of the most important aspects of ethics in an organization which indicates the virtuous behavior of its members. Organizational virtue means creation, extension, advocation, and training of behavior, customs, doings, and high inclination at the individual and collective level in an organization (Rego, Ribeiro, Cunha, \& Jesuino, 2011). So, every individual's actions, collective activities, cultural features, and every process which extends and broadens a virtue in an organization may lead to organizational virtue (Cameron, Bright, \& Caza, 2004). With respect to the importance of spreading professional ethics, in this research we will analyze the variables having an effect on that. So, the aim of this research is to analyze the effect of organizational virtue on professional ethics of Ardabil's Maskan Bank staff.

\section{The Literature Review}

Virtue is the acquisitive quality of human; if you possess and use it, you will be able to achieve internal advantages of actions and if you lack it, you cannot achieve such outcomes. It is argued that virtue is an affective quality which is desirable for everybody who analyzes and thinks of it. It is a quality which brings indulgence to impartial observers and provides admiration. Moreover, indulgence or intolerance which derives from every action or quality of mind identifies whether it is a virtue or villainy (Khazaei, 2010). According to Bright, Winn, and Kanov (2013), virtue refers to achieving the highest ideal in human's attitude. In functional definition, virtue is defined as a quality that makes a person do the best of his/her duty, move toward prosperity, and take positive and useful actions.

Virtue Ethics is a normal theory and is distinguished from utilitarian and duty-oriented theories because of its virtue-oriented nature. The famous distinction between virtue ethics and the theories mentioned above is that it emphasizes virtue and moral behavior, but utilitarianism assesses the moral act based on the highest usefulness criterion for people and duty-oriented theory assesses it based on the criterion of being in accordance with moral rules while obeying the rules is a stimulus to be so (Khazaei, 2010). Organizational virtue means creation, extension, advocation, and training of behavior, customs, doings, and high inclination at the individual and collective level in an organization (Rego et al., 2011). Organizational virtue pays attention to three important principles, namely human influence, moral desirability, and social improvement. Based on these principles, Cameron et al. (2004) suggested a model which 
has five factors from organizational virtue, including optimism, trust, compassion, integrity, and forgiveness.

Optimism refers to inclination to trust, expect or hope that things will be good in spite of the present troublesome experience. Optimism may act as enduring the mental and physical problems in the future and improvement of strategies against them (Nes \& Segerstorm, 2006).

Considering trust, organizational trust shows that goodwill, consideration, and respect are dominant in the organization and people respect each other and their leaders (Rego et al., 2011).

Compassion means promotion of acts such as being careful of each other in an organization.

Forgiveness means that people forgive mistakes quickly and these mistakes are being used as opportunities for learning in fields identified through high standards of function (Rego et al., 2011).

Integrity refers to promotion of honesty, trust, and rectitude in the organization (Cameron et al., 2004).

Virtue-oriented organizations are those formed on moral virtues and their manager and staff have virtue and their relationships and interactions are regulated based on moral virtues (Hejazifar \& Bageri Kiani, 2011). From an organizational perspective, each organization has two levels including people, who are its members, and the whole organization as a group of people. In fact, people have two roles, namely an individual role and an organizational role. Here we will analyze the virtues of each level:

\section{Virtue at an Individual Level}

a) Having Fondness for God: God's remembrance is the foundation in Islamic morality and basically the foundation in spirit of every worship and moral value.

b) Good Faith: According to moral ethics, performance only is not sufficient rather it is important to have stimulus and intention in performance because they make the acts to be valuable (Sadegi, 2005).

c) Belief in Hereafter: It is just to be guided by Quranic and Holy values and directed to real prosperity. In respect of the correct concept of Islamic management, that is, management based on the Islamic values, it is obvious that Islamic management is really the same as management on the base of hereafter belief.

d) Accountability: It is one of the most important and effective cases in philosophical, religious, moral, and juridical issues. Accountability means to want something from somebody and is applicable in cases in which the plaintiff follows up his/her request from the person in charge and at least knows that person responsible for his or her behavior and responsible for its consequences whether they are in accordance with his/her request or not in order to rebuke the man in charge. 


\section{Virtue at an Organizational Level}

a) Human Affection: It is actually a holy and celestial light from God and is considered as a grace and one of the human life's privileges. Human affection is an internal endowment to like others in spite of the other intuitions which lead to self-centeredness. This internal endowment makes human be able to find an internal inclination toward fellowmen based on kindness in order to create a heartfelt relationship. Affection weakens self-centeredness and makes the other virtue grow by leading the man toward the fellowmen (Sadaat, 1998). Because an organization is an environment in which people work together, human affection should be seriously established between its members in order that the organization moves toward virtue orientation (Sheidanshid, 2004).

b) Justice: Early philosophers believe that justice is the origin of all other types of virtue. They consider that the same as virtue itself. It is known as the total of other virtues that exist in politics and include all of the government's duties: So it brings right, safety, welfare, integrity, and prosperity for people (Mesbah, 2009). Several intellectuals have called it as a virtue.

c) Respecting the Law and Hierarchy: This leads to departmental discipline and makes bureaucratic issues be consistent and brings up a situation without anarchy. In addition, it leads to integrity in the organization.

d) Serving Others: Obligatory acts and recommended acts of Islam not only depend relatively on serving others but also are synonyms with it. Monotheism in obligatory acts arena means to acknowledge the origin of being and all of beings owe their creation and survival to it. Justice is representative of lawfulness of grace in universe. Prophecy and leadership implies the obligation of virtual grace of guidance. Judgment Day is an arena to recompense to those who are good doers and have good will and punish those who are disloyal to life, ideals, and fundamental needs of human. To believe in leadership and exoneration means entering into an alliance with servers who serve human and exoneration from enemies of human.

\section{Professional Ethics}

Professional ethics is one of the new branches of ethics which tries to answer the moral questions of different professions. Nowadays, ethics has the role of guideline in companies, and specialists of strategic management identify professional ethics as a precondition for strategic management (Faramarz Garamaleki, 2009). At first, work ethics and business ethics were used as the concept of professional ethics. These days, the former usage is still used by some researchers to define it. Different definitions have been proposed for professional ethics:

Work Ethics: Work ethics refers to committing the physical and mental energy of every individual or group to the opinion of the whole to acquire the internal force and capacity of group and individual, then use them for the improvement (Cadozier, 2002). 
Individual Ethics: It is the responsibility of a person against his or her own behavior as a human. Work ethics is the responsibility of a person against his or her job behavior as an employer (Moberg \& Seabright, 2000).

Professional Ethics: As a branch of ethics, it deals with moral duties and problems within the job. Some infer from its definition that it guides the man to the identified situation accompanying special ethics (Garamaleki, 2009). Professional ethics is one of the new branches of ethics which tries to answer the ethical questions of different professions and attaches specific principles to it (Hartog \& Winstonly, 2002).

There are two outstanding features in all of the definitions above and they are gentility of the person and individualistic attitude, and limitation of responsibilities and moral obligations of the person within the job. This view seems to be a kind of reductionist view which underestimates professional ethics, because the group identity is more important than the job of an individual. There have been recently many arguments of professional ethics based on this view in the field of resource management most of which are elaborated with respect to the management of human resources (Faramarz Garameleki, 2009).

Based on this case, ethical responsibilities of company and organization have been expressed in the new concept of professional ethics which is more comprehensive than the traditional definition. Company, in this view, has two responsibilities as a legal entity, namely responsibility of penal code and ethical responsibilities.

Ethical responsibilities of a company are more complex than those of a person and a job. In other words, ethical responsibilities of a company include all dimensions of the organization which in turn include work ethics. Of course, professional ethics includes not only the work ethics but also the rules of the job.

Cadozier (2002) suggests some points about the features of people who have professional ethics:

Accountability: In this case, the person is responsible for his or her decisions and their consequences. He should have good morality to be a role model for others and pay attention to rectitude and fame. He should sincerely try to do his best in carrying out all his responsibilities.

Virtue and Competitiveness: The person tries to be the best in every field. He has selfconfidence and works hard to be skillful in his job. He is not satisfied with the present situation and wants to progress through acceptable ways and will not violate the rules.

Honesty: He is a conscientious and courageous man who does not like hypocrisy and takes into account honesty.

Respecting Others: He is punctual and respects others' rights and opinions. He allows others to make decisions and does not just take into account his own benefits.

Respecting Values and Social Norms: He respects social values and norms, attends social activities, and is unbiased when faces other cultures. 
Justice: He looks for justice and is unbiased in judgment. He does not discriminate between people with respect to their culture, social, and economic classes and races.

Compassion: He is compassionate, protects others, pays attention to their feelings, and knows their problems as his own (Cadozier, 2002).

Loyalty: He is committed to his duties and is confidant (Cadozier, 2002). Zionts, Shellady, and Zionts (2006) state some factors fundamental to professional ethics, namely professional independency of scientific ethics, professional self-understanding, objectivity, impartialness, and moving beyond the concept of livelihood.

We can use the strategic principles of professional ethics in Islam to identify the practical components of professional (Islamic) ethics. The main strategic principles (in Islam) are unconditional respect to human, respect for their freedom, establishment of justice, and trust in personal behavior and insight (Ameli, 2002). In Islamic Republic bureaucracy, professional ethics should have Islamic identity and be shaped based on Islamic ethics. We point to four reasons that imply why we should have Islamic identity in professional ethics in Iran: a) most people believe in Islamic system with respect to their culture (Faramarz Garamaleki, 2009); b) inseparability of ethics from religion as mentioned in Islam (Khani Jazani, 2003); c) the need to create dynamicity within Islamic culture with regard to facing globalization; d) establishment of a government based on religion and emphasizing the approval of Islamic rules as mentioned in Article 8 in constitution that is obligatory. In the last case, it is necessary to mention that in Islamic professional ethics, the final criterion of ethics is summum bonum, that is, the same as what God wants.

\section{The Study}

With respect to the review of the literature, organizational virtue means creating, extending, supporting, and developing behavior, customs, deeds, and high inclination such as compassion, forgiveness, trust, and loyalty at the individual and collective levels in organizations (Rego et al., 2001). The factors contributing to organizational virtue are optimism, trust, compassion, integrity, and forgiveness (Khoshouei \& Nouri, 2013). Professional ethics is a set of accepted moral actions and reactions regulated by professional organizations to provide the desirable social relationships for their members executing professional duties. In this study, professional ethics has eight components based on the Cadozier's model (2002), namely accountability, virtue and competitiveness, honesty, respect for others, respect towards social values and norms, justice, compassion for others, and loyalty (Amiri Hemmati, \& Mobini, 2010). Based on these components, the conceptual model of the study is presented in Figure 1. 


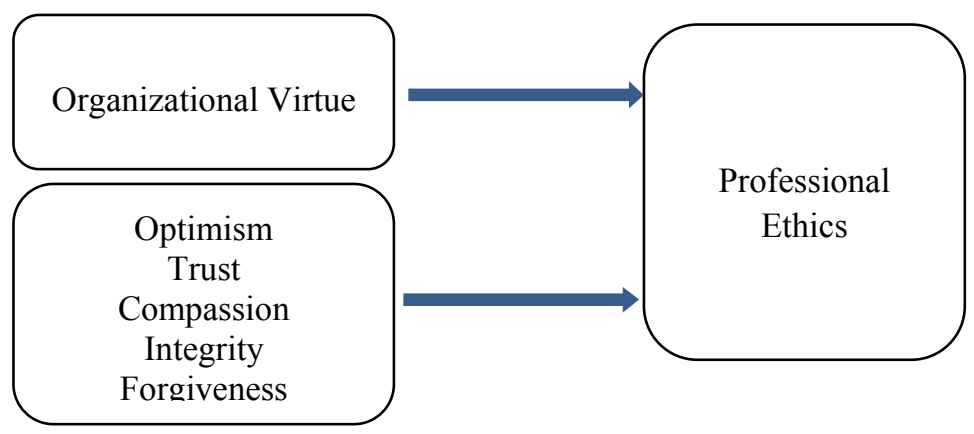

Figure 1. Research Conceptual Model

\section{Research Hypotheses}

The following hypotheses guided the study:

- $\quad \mathbf{H}_{1}$ : Organizational virtue has a significant and positive effect on professional ethics.

- $\quad \mathbf{H}_{2}$ : Components of organizational virtue have positive and significant effect on the staff's professional ethics.

\section{Method}

This applied study is a descriptive-survey research by using a questionnaire. The population included all the staff in Maskan Bank in Ardabil province amounting to 180. To determine the sample size, we used Morgan's Table and randomly selected the participants leading to 118 people. The questionnaire was standardized (Khoshouei \& Nouri, 2013), but in order to ensure its reliability and content validity, we asked several professors and experts' opinions with respect to its aim and nature. After revision and receiving confirmation, we distributed the questionnaire. We used Cronbach's alpha to calculate the consistency coefficient of the questionnaire. The Cronbach's alpha coefficient for the variables of organizational virtue and professional ethics were 0.77 and 0.88 , respectively indicating that the questionnaire was reliable. Following this, to test the hypothesis and analyze the data, we employed Pearson's correlation coefficient and multivariate regression in SPSS.

\section{Results}

We conducted the study with 118 participants. Following this, $82.2 \%$ of the respondents were male and $17.8 \%$ were female. From a frequency point of view, the most frequent age range was $30-40(65.3 \%)$ and the level of education was B.A. (54.2\%). The most frequent job background was 10 years $(50 \%)$.

According to central tendency and dispersion, organizational virtue and professional ethics of the staff scored higher than the mean, 3.82 and 3.99, respectively. The other results were compassion (4.54), optimism (4.28), integrity (4.05), confidence (3.86), and forgiveness (3.37). The results of the Kolmogorov-Smirnov test demonstrated that the coefficient of professional ethics was 0.96 and it was 0.82 for organizational virtue. Both of them were significant and the level of significance was 0.95 which was higher than 0.05 . So, it can be concluded that the distribution of professional ethics and organizational virtue was normal. 
Result of Regression Analysisis showed that organizational virtue predicts $55 \%$ of the variation related to the professional ethics.

Table 1 presents the results of multivariate regression for the components of organizational virtue and professional ethics.

Table 1

Results of Multivariate Regression for the Components of Organizational Virtue and Professional Ethics

\begin{tabular}{|c|c|c|c|c|c|}
\hline \multirow[t]{2}{*}{ Prediction Variable } & \multirow{2}{*}{$\frac{\text { Standard Coefficient }}{\text { BETA }}$} & \multicolumn{2}{|c|}{ Non-Standard Coefficient } & \multirow[t]{2}{*}{$\mathrm{T}$} & \multirow[t]{2}{*}{$\mathrm{P}$} \\
\hline & & SD & $\mathrm{B}$ & & \\
\hline Constant & 0.49 & 0.16 & 2.20 & 13.41 & 0.00 \\
\hline Optimism & 0.34 & 0.03 & 0.19 & 5.12 & 0.00 \\
\hline Trust & 0.34 & 0.02 & 0.11 & 4.16 & 0.00 \\
\hline Compassion & 0.27 & 0.05 & 0.11 & 2.30 & 0.00 \\
\hline Consistency & 0.24 & 0.06 & 0.18 & 1.29 & 0.00 \\
\hline Forgiveness & 0.49 & 0.03 & 0.15 & 1.49 & 0.00 \\
\hline
\end{tabular}

Table 1 shows that the observed $\mathrm{P}$ in all variables is significant. Optimism (0.49), trust (0.34), compassion (0.34), integrity (0.27), and forgiveness $(0.24)$ can predict professional ethics in which optimism (0.49) has the highest and forgiveness (0.24) has the lowest predictive ability.

\section{Discussion and Conclusion}

Professional ethics looks like a double-edged sword; one edge is threat and the other is opportunity. Due to the fact that professional ethics has significant effect on activities and outcomes of an organization which can finally lead to success, weakness in ethical system can be threatening. The findings of this study revealed that the professional ethics of the organization's staff was medium. In contrast, it revealed that organizational virtue can predict $55 \%$ of the variance related to professional ethics. It can be concluded that if an organization improves its virtue, it will develop the professional ethics of its staff. According to the results, optimism (0.49), trust (0.34), compassion (0.34), integrity (0.27), and forgiveness (0.24) can predict professional Optimism (0.49), trust (0.34), compassion (0.34), consistency $(0.27)$, and forgiveness (0.24) where optimism (0.49) has the highest predictive ability and forgiveness (0.24) has the lowest capability. So, the managers should take into account maximizing sense of optimism in their staff. They should create a sense of success in their staff in spite of the difficulties and challenges. Staff should be respected with good faith, and trust should be boosted among the members of the organizations. They should also have such compassionate and kind atmosphere that the staff tries to increase the organization's integrity by developing honesty and trust. A virtue-oriented organization should be forgiving that overlooks the staff's mistakes (of course overlooking should be realistic if the mistakes are confirmed to be unintentional) and these mistakes should function as eye-opener to the staff. After his successful study which led to the recognition of the relationship between organizational virtue and citizenship, Rego, one of the most famous researchers in the field of organizational virtue, conducted another study on the relationship between organizational virtue and organizational commitment. The results of this study showed that organizational virtue has positive and significant effect on organizational commitment. Satisfaction in this study was analyzed as the 
moderator variable (Rego et al., 2011). Fabian (2012) also studied the relationship between organizational virtue and work preoccupation. The results revealed that organizational virtue had positive effect on work preoccupation.

The findings of this study should be viewed within the context of its limitations. Future studies should extend this work and consider other measures. Moreover, future studies should preferably take advantage of longer and more representative samples, allowing the results to be more generalizable.

\section{References}

Ameli, M. (2002). Examining the theoretical foundations of professional ethics in Islam (Master's thesis). Tehran: Iranian Institute of Philosophy.

Amiri, A. N., Hemmati, M., \& Mobini, M. (2010). Ethics: The necessity for an organization. Journal of Moral Ethics, 1(4), $137-159$.

Bright. D., Winn, B., \& Kanov, J. (2014). Reconsidering virtues: Differences of perspective in virtue ethics and positive social science. Journal of Business Ethics, 119(4), 445-460.

Cadozier, V. (2002). The moral profession: A study of moral development and professional ethics. Retrieved from www.proquest.com.

Cameron, K. S., Bright, D., \& Caza, A. (2004). Exploring the relationships between organizational virtuousness and performance. American Behavior Scientist, 47(6), 766-790.

Fabian. O. (2012). Are good morals often reciprocated: perceptions of organizational virtuousness and optimism as predictors of work engagement? Asian Journal of Social Science \& Humanities, 1(3), 188-198.

Faramarz Gharamaleki, A. F. (2009). An introduction to professional ethics ( $2^{\text {nd }}$ ed.). Tehran: Saramad Press.

Hartog, M., \& Winstanley, D. (2002). Ethics and human resource management: Professional development and practice. Business \& Professional Ethics Journal, 21, 3-9.

Hejazifar, S., \& Bagheri Kani, S. (2011). Central virtues in virtue-centered organizations. Journal of Islamic \& Management Research, 1(3), 117-143.

Jos, P. H. (2006). Social contract theory implications for professional ethics. The American Review of Public Administration, $36,139-155$

Khani Jazani, J. (2003). Business ethics and marketing in Islamic economics. Management Excellence, 2/3, 131-144.

Khazaei, Z. (2010). Virtue ethics. Religious Thought, 14, 74-61.

Khoshouei, M. S., \& Nouri, A. (2013). Factor structure of organizational Virtuousness and the role of organizational citizenship behavior in it. Knowledge \& Research in Applied Psychology, 14(4), 26-34.

Mesbah, M. T. (2009). Justice and progress in the religious state. Islamic Government, 14(2), 5-14.

Moberg, D. J., \& Seabright, M. A. (2000). The development of moral imagination. Business Ethics Quarterly, 10(4), 845-884.

Nes, L. S., \& Segerstrom, S.C. (2006). Dispositional optimism and coping: A meta-analytic review. Personality \& Social Psychological Review, 10(3), 235-251.

Pennino, C. M. (2002). Is decision style related to moral development among managers in the US? Journal of Business Ethics, 41(4), 337-347.

Rego, A., Ribeiro, N., Cunha, M. P., \& Jesuino, J. C. (2011). How happiness mediates the organizational virtuousness and affective commitment relationship. Journal of Business Research, 64(5), 524-532.

Sadat, M. A. (1998). Islamic ethics (20 th ed.). Tehran: Samt.

Sadeghi, M. (2005). Virtue-oriented ethics in views of the late Naraghi and Imam Khomeini. Mishkat al-Nour, 30/31, 12-32.

Sheidanshid, H. A. (2004). Reason in ethics. Qom: Howzeh va Deneshgah.

Zionts, L. T, Shellady, S. M., \& Zionts, P. (2006). Teachers' perceptions of professional standards: Their importance and ease of implementation. Preventing School Failure, 50(3), 5-12. 